\title{
Age at Menarche among School Adolescents Girls in Saudi Arabia: Environmental Factors
}

\author{
Kholoud Khalaf Al Harbi, Maryam Munahi AL-Qahtani, Gihan Yousef, Sayed Ibrahim Ali* \\ College of Medicine, King Faisal University, Al-Ahsa, Saudi Arabia \\ Email: ^drsamas38@gmail.com
}

How to cite this paper: Al Harbi, K.K., AL-Qahtani, M.M., Yousef, G. and Ali, S.I. (2018) Age at Menarche among School Adolescents Girls in Saudi Arabia: Environmental Factors. Open Journal of Preventive Medicine, 8, 283-290.

https://doi.org/10.4236/ojpm.2018.89024

Received: December 11, 2017

Accepted: September 16, 2018

Published: September 19, 2018

Copyright ( $) 2018$ by authors and Scientific Research Publishing Inc. This work is licensed under the Creative Commons Attribution International License (CC BY 4.0).

http://creativecommons.org/licenses/by/4.0/

\begin{abstract}
Background: Menarche is the first menstrual period of a girl at puberty. The timing of menarche is significant for health in future life. Saudi Arabia has developed immensely over the last three decades as evidenced by the economic and health sectors throughout all parts of the vast Kingdom. The current study measured the menarche age of school adolescents Girls in Saudi Arabia and explored environmental factors that could impact the onset of menarche. Method: This cross-sectional study was conducted on 1486 healthy Saudi school adolescents' girls between 10 - 19 years old. The data were collected in 2016 using self-administered questionnaires. Health status, dietary intake, physical activities and parent's education were recorded along with other environmental factors. Data were analyzed using SPSS version 17.1. Results: Out of 1486, 767 girls (51.6\%) had experienced menarche with a mean age of $12.46 \pm$ 1.57; 681 girls $(45.8 \%)$ had experienced menarche at age of $13-15 ; 38$ girls (2.6\%) had experienced menarche at age of 16. A significant association between menarche and social factors was detected. Besides, the study discovered a significant association between menarche and the lifestyle of the studied groups.
\end{abstract}

\section{Keywords}

Menarche, Adolescents Girls, Saudi Arabia

\section{Introduction}

The first menstrual cycle in the adolescent's life is called menarche. It is a late event of puberty and an important indicator of sexual maturation. This milestone typically occurs within two to three years after puberty onset and is characterized by thelarche ${ }^{1}$, which is represented by the development of the mammary bud [1].

${ }^{1}$ Thelarche is usually the first clinically recognizable stage of puberty and typically occurs between 10 and 12 years of age and is characterized by the appearance of a "breast bud". 
Regarding the age group, menarche usually occurs between the ages of 12 and 13 years. Approximately $50 \%-80 \%$ of the variation in puberty onset age and milestones is determined by genetic and environmental factors; however, the substantial decline at the age at menarche between the early 19th century and the mid-20th century was associated with a significant environmental factor like improvement in nutrition and living conditions during the process of modern civilization [2].

Earlier menarche is associated with an increased risk of some diseases, such as breast cancers, gynecological cancers and various cardiovascular diseases [3].

Girls with early menarche exhibited elevated blood pressure and glucose intolerance compared with girls who matured later. Overall, earlier menarche (before 12 years) results in higher mortality [3]. On the other hand, there is a positive correlation between early menarche and high bone mineral density. Recent data suggest that age at menarche is significantly associated with body composition, insulin sensitivity and blood lipid levels [4].

The declining trend in the age at menarche has undergone an apparent stabilization since the 1960s. However, in the last two decades, a trend toward menarche anticipation has been reported, especially in developing countries [5].

Identification of the environmental factors that contribute to puberty and the timing of menarche may add to our understanding of the physiological mechanism of this trait and the associated fertility and health risks in Saudi Arabia.

In the light of the abovementioned and according to the importance of determining the age at menarche in adolescents and its psychological and physical impacts, this study was conducted to verify the age at menarche and its related environmental factors among school adolescent's girls in Saudi Arabia.

\section{Materials and Methods}

Following the cross-sectional descriptive approach, this study was conducted to determine the age at menarche and its related environmental factors among school adolescent's girls in Saudi Arabia.

The total population of Saudi Arabia is 30,493,418 and the study sample was 1486 of Saud school adolescents' girls between ages 10 and 19 . The study sample was calculated according to the following formula:

$$
n=Z_{1-\alpha / 2}^{2}(1-p) / \varepsilon^{2} P
$$

The sample included adolescents from all regions of Saudi Arabia as follow:

\begin{tabular}{cc}
\hline Parentage & Region \\
\hline 35.15 & The Central Region \\
41 & The Western Region \\
2.35 & The Southern Region \\
16.5 & The Eastern Region \\
11.05 & The Northern Region \\
\hline
\end{tabular}


The data were collected in 2016 using self-administered questionnaires. Health status, dietary intake, physical activities and parents' education were recorded along with other environmental factors. Data were analyzed using SPSS version 17.1.

The researchers chose questionnaires since interviews would be difficult due to the sensitivity of this issue in the Saudi community.

The first part of the questionnaire was about the place of living. The second part of the questionnaire was about age at menarche and school grade at which menarche has started (Early menarche was defined as, <12-year, normal menarche as $\geq 13$ and $<15$-year, and late menarche as $\geq 16$-year). The third part of the questionnaire was about social factors (i.e. type of housing, parents' occupation, parents' education) and health status (i.e., diet, daily intake of soda, milk, fruits, and vegetables). In addition, this part included questions about type and duration of physical exercises (i.e. running, dancing, jogging, swimming, or other sports) along with other daily habits (i.e. reading, watching TV, gaming, and sleeping).

Data were expressed as number (percentage). Comparisons were performed by Chi-square test for categorical variables. Logistic regression models were used to evaluate the association between menarche and study variables while adjusting for various confounders. Analysis of the data was carried out using SPSS 17.1.

\section{Results}

In this study, 1486 Saudi school adolescents' girls between 10 - 19 years old from the five main regions of Saudi Arabia were targeted in this study. Depending on the population ratio of each region, Central (35.15\%), Western (41\%), Southern (2.35\%), Easter (16.5\%) and Northern (11.05\%), students from all socio-economic classes were enrolled in the study. The mean age and standard deviation $(\mathrm{SD})$ of the study group were $12.46( \pm 1.57)$ years. Most of the participants $(80 \%)$ were the first and second child of the family and lived in their personal houses. Only $9.2 \%$ of mothers and $14 \%$ of fathers had an academic education.

\subsection{Demographic Data}

Table 1 shows the demographic data of the target sample. It shows that there was no significant difference in the mean age at menarche between Saudis and non-Saudis. The number of girls who had early menarche is 767 (51.6\%) in all regions and the number of girls who had normal menarche is $681(45.8 \%)$ in all regions. However, the number of girls who had late menarche is $38(2.6 \%)$. The result shows that there is no significant association between the age of menarche and region of living where the highest "Early" percentage was in the eastern and central areas: 297 and 206 respectively.

(767) $51.6 \%$ of the entire sample had early menarche while 681 (45.8\%) had normal menarche and 38 (2.6\%) of the sample had late menarche. 
Table 1. Demographic data.

\begin{tabular}{cccccc}
\hline Characteristics & Early (NO. \%) & NORMAL (NO. \%) & Late (NO. \%) & $P$ & Chi-square \\
\hline Nationality & & & & & \\
Saudi & $735 \%-49 \%$ & $662 \%-44.5 \%$ & $36 \%-2.4 \%$ & 0.312 & 2.330 \\
Non-Saudi & $32 \%-2.2 \%$ & $19 \%-1.3 \%$ & $2 \%-0.1 \%$ & & \\
Region & & & & & \\
East & $297 \%-20.0 \%$ & $250 \%-16.8 \%$ & $12 \%-37.6 \%$ & & \\
Western & $147 \%-9.9 \%$ & $123 \%-8.3 \%$ & $13 \%-19.0 \%$ & & \\
South & $66 \%-4.4 \%$ & $53 \%-3.6 \%$ & $2 \%-8.1 \%$ & 0.151 & 12.004 \\
North & $51 \%-3.4 \%$ & $60 \%-4.0 \%$ & $0 \%-7.5 \%$ & & \\
Central & $206 \%-13.9 \%$ & $195 \%-13.1 \%$ & $11 \%-0.7 \%$ & & \\
Age at menarche & $767 \%-51.6 \%$ & $681 \%-45.8 \%$ & $38 \%-2.6 \%$ & - & - \\
\hline value significant on 0.05. & & & & \\
\hline
\end{tabular}

\subsection{Social Characteristics}

Table 2 shows that a large number of girls who have a mother with low income had menarche early and normal, while girls who have mothers with a universal degree had early normal menarche. However, fathers' occupation and education have no association with the age of menarche. The results show that girls who live in their own houses have menarche at early and normal age; this could be related to the economic situation of the family.

\subsection{Life Style}

Table 3 shows that there is a significant relationship between doing sports, drinking soda, eating fast food and sedentary behavior. Those who are not doing exercises have menarche at early and normal ages. Those who drink soda 2 - 3 times per week have menarche at early and normal age. Girls with sedentary behavior for more than 5 hours have menarche at early and normal age.

\section{Discussion}

The mean age of menarche in our study was $12.46 \pm 1.57$, with the minimum and maximum age of 10 and 19 years old. This finding is similar to the study in Kuwait (12.41 years) [6], Istanbul (12.74 years) [7], Tehran (12.68 years) [8], Maharashira, India (12.62 years) [9], Chile (12.7 years) [10], France (12.5 years) [11], Poland (12.77 years) [12], Spain (12.83 years) [13], and different from South Ethiopia (13.9 years) [14], Ethiopia, Mekelle (14.24 years) [15], Nigeria (13.66 years) [16], Uganda (13.3 - 13.6 years) [17], and North Korea (16 years) [18].

The difference in the menarche age can be due to environmental and social factors. For example, it is stated that African girls have a higher age at menarche [19]. Early menarche was seen in $10.3 \%$ of students compared to $8.5 \%$ in Kuwait [6], 7.8\% in white American girls [20], and 6.1\% in Nigeria [16]. The various rates of early menarche may be due to the different definition in different studies. 
Table 2. Social characteristics.

\begin{tabular}{|c|c|c|c|c|c|}
\hline Characteristics & Early (NO. \%) & NORMAL (NO. \%) & Late (NO. \%) & $P$ & Chi-square \\
\hline \multicolumn{6}{|c|}{ Father's occupation } \\
\hline High income & $233 \%-15.7 \%$ & $205 \%-13.8 \%$ & $14 \%-0.9 \%$ & \multirow{3}{*}{0.909} & \multirow{3}{*}{1.005} \\
\hline Middle income & $379 \%-25.5 \%$ & $341 \%-23.0 \%$ & $18 \%-1.2 \%$ & & \\
\hline Low income & $155 \%-10.4 \%$ & $133 \%-9.0 \%$ & $6 \%-2.0 \%$ & & \\
\hline \multicolumn{6}{|c|}{ Mother's occupation } \\
\hline High income & $22 \%-1.5 \%$ & $18 \%-1.2 \%$ & $6 \%-0.4 \%$ & \multirow{3}{*}{0.001} & \multirow{3}{*}{21.317} \\
\hline Middle income & $275 \%-18.5 \%$ & $236 \%-15.9 \%$ & $11 \%-0.7 \%$ & & \\
\hline Low income & $470 \%-31.6 \%$ & $427 \%-28.7 \%$ & $21 \%-1.4 \%$ & & \\
\hline \multicolumn{6}{|l|}{ Father's education } \\
\hline Uneducated & $52 \%-3.5 \%$ & $32-2.2 \%$ & $4 \%-0.3 \%$ & \multirow{6}{*}{0.084} & \multirow{6}{*}{16.596} \\
\hline Preparatory & $112 \%-7.5 \%$ & $131 \%-8.8 \%$ & $4 \%-0.3 \%$ & & \\
\hline Secondary & $205 \%-13.8 \%$ & $190 \%-12.8 \%$ & $6 \%-0.4 \%$ & & \\
\hline Universal & $285 \%-19.2 \%$ & $232 \%-15.6 \%$ & $15 \%-1.0 \%$ & & \\
\hline Master & $74 \%-5.0 \%$ & $55 \%-3.7 \%$ & $5 \%-0.3 \%$ & & \\
\hline Doctorate & $39 \%-2.6 \%$ & $41 \%-2.8 \%$ & $4 \%-0.3 \%$ & & \\
\hline \multicolumn{6}{|l|}{ Mother's education } \\
\hline Uneducated & $101 \%-6.8 \%$ & $94 \%-6.3 \%$ & $7 \%-0.5 \%$ & \multirow{6}{*}{0.001} & \multirow{6}{*}{46.544} \\
\hline Preparatory & $135 \%-9.1 \%$ & $132 \%-8.9 \%$ & $5 \%-0.3 \%$ & & \\
\hline Secondary & $165 \%-11.1 \%$ & $136 \%-9.2 \%$ & $9 \%-0.6 \%$ & & \\
\hline Universal & $329-22.1 \%$ & $273-18.4 \%$ & $8-0.5 \%$ & & \\
\hline Master & $24-3.1 \%$ & $34-2.3 \%$ & $61-4.1 \%$ & & \\
\hline Doctorate & $13-1.7 \%$ & $12-0.8 \%$ & $31-2.1 \%$ & & \\
\hline \multicolumn{6}{|l|}{ Housing type } \\
\hline Property & $583 \%-39.2 \%$ & $553 \%-37.2 \%$ & $27 \%-1.8 \%$ & \multirow{2}{*}{0.032} & \multirow{2}{*}{6.912} \\
\hline Rent & $184 \%-12.4 \%$ & $128 \%-8.6 \%$ & $11 \%-0.7 \%$ & & \\
\hline
\end{tabular}

Table 3. Life style characteristics.

\begin{tabular}{|c|c|c|c|c|c|}
\hline Characteristics & Early (NO. \%) & NORMAL (NO. \%) & Late (NO. \%) & $P$ & Chi-square \\
\hline \multicolumn{6}{|l|}{ Doing exercise } \\
\hline Every day & $65 \%-4.4 \%$ & $96 \%-6.5 \%$ & $11 \%-0.7 \%$ & & \\
\hline No & $395 \%-26.6 \%$ & $313 \%-21.1 \%$ & $14 \%-0.9 \%$ & & \\
\hline 2 - 3 times/week & $140 \%-9.4 \%$ & $133 \%-9.0 \%$ & $9 \%-0.6 \%$ & 0.001 & 34.056 \\
\hline 4 - 5 times/week & $74 \%-5.0 \%$ & $42 \%-2.8 \%$ & $3 \%-0.2 \%$ & & \\
\hline Monthly & $93 \%-6.3 \%$ & $97 \%-6.5 \%$ & $1 \%-0.1 \%$ & & \\
\hline \multicolumn{6}{|l|}{ Drinking Soda } \\
\hline Every day & $97 \%-6.5 \%$ & $109 \%-7.3 \%$ & $10 \%-0.7 \%$ & & \\
\hline No & $125 \%-8.4 \%$ & $105 \%-7.1 \%$ & $4 \%-0.3 \%$ & & \\
\hline 2 - 3 times/week & $269 \%-18.1 \%$ & $252 \%-17.0 \%$ & $12 \%-0.8 \%$ & 0.012 & 19.682 \\
\hline 4 - 5 times/ week & $82 \%-5.5 \%$ & $83 \%-5.6 \%$ & $8 \%-0.5 \%$ & & \\
\hline Monthly & $194 \%-13.1 \%$ & $132 \%-8.9 \%$ & $4 \%-0.3 \%$ & & \\
\hline \multicolumn{6}{|l|}{ Eating fast food } \\
\hline Every day & $26 \%-1.7 \%$ & $17 \%-1.1 \%$ & $4 \%-0.3 \%$ & & \\
\hline No & $65 \%-4.4 \%$ & $62 \%-4.2 \%$ & $3 \%-0.2 \%$ & & \\
\hline 2 - 3 times/week & $322 \%-21.7 \%$ & $267 \%-18.0 \%$ & $11 \%-0.7 \%$ & 0.002 & 24.733 \\
\hline 4 - 5 times/ week & $36 \%-2.4 \%$ & $55 \%-3.7 \%$ & $7 \%-0.5 \%$ & & \\
\hline Monthly & $318 \%-21.4 \%$ & $280 \%-18.8 \%$ & $13 \%-0.9 \%$ & & \\
\hline
\end{tabular}




\section{Continued}

Sedentary behavior

\begin{tabular}{|c|c|c|c|c|}
\hline Hour & $117 \%-7.9 \%$ & $110 \%-7.4 \%$ & $6 \%-0.4 \%$ & \\
\hline 3 hours & $146 \%-9.8 \%$ & $118 \%-7.9 \%$ & $9 \%-0.6 \%$ & 055 \\
\hline 4 hours & $120 \%-8.1 \%$ & $109-7.3 \%$ & $7 \%-0.5 \%$ & \\
\hline More than 5 hours & $384 \%-25.8 \%$ & $344 \%-23.1 \%$ & $16 \%-1.1 \%$ & \\
\hline
\end{tabular}

In the current study, the high percentage of Saudi girls have menarche at early ( $<12$-year) and normal (as $\geq 13$ and $<15$-year) ages. This is due to a variety of environmental factors like socioeconomic status, mother occupation, mothers' education, and housing type affected the age at menarche. The results have revealed the existence of a strong association between mother's occupation and menarche at an early age. In addition, the study revealed strong association between mother's education and early menarche where those have mothers with a universal degree have menarche at a normal age. Girls who live in their own house had menarche at a normal age. In short, those who belong to the high class and live with less stress had menarche at a normal age.

Regarding food habits, the study has shown that girls who have healthy food consumption had menarche at a normal age, yet those who consume carbonated drinks regularly had early menarche. Besides, girls consuming fast food at high rates had menarche at a late age.

Finally, maintaining a healthy life with periodical exercising lead to normal menarche, but having no exercises leads to having menarche at an early age.

Finally, out of 1486, 767 girls (51.6\%) had experienced menarche with a mean age of $12.46 \pm 1.57 ; 681$ girls $(45.8 \%)$ had experienced menarche at age of 13 $15 ; 38$ girls $(2.6 \%)$ had experienced menarche at age of 16 . A significant association between menarche and social factors was detected. Besides, the study discovered a significant association between menarche and the lifestyle of the studied groups.

\section{References}

[1] Tanner, J.M., Whitehouse, R.H., Marshall, W.A. and Carter, B.S. (1975) Prediction of Adult Height from Height, Bone Age, and Occurrence of Menarche, at Ages 4 to 16 with Allowance for Midparent Height. Archives of Disease in Childhood, 50, 14-26. https://doi.org/10.1136/adc.50.1.14

[2] Palmert, M.R. and Boepple, P.A. (2001) Variation in the Timing of Puberty: Clinical Spectrum and Genetic Investigation. The Journal of Clinical Endocrinology \& Metabolism, 86, 2364-2368. https://doi.org/10.1210/jcem.86.6.7603

[3] Lakshman, R., Forouhi, N.G., Sharp, S.J., Luben, R., Bingham, S.A., Khaw, K.T. and Ong, K.K. (2009) Early Age at Menarche Associated with Cardiovascular Disease and Mortality. The Journal of Clinical Endocrinology \& Metabolism, 94, 4953-4960. https://doi.org/10.1210/jc.2009-1789

[4] Feng, Y., Hong, X., Wilker, E., Li, Z., Zhang, W., Jin, D. and Xu, X. (2008) Effects of Age at Menarche, Reproductive Years, and Menopause on Metabolic Risk Factors for Cardiovascular Diseases. Atherosclerosis, 196, 590-597. 
https://doi.org/10.1016/j.atherosclerosis.2007.06.016

[5] Euling, S.Y., Herman-Giddens, M.E., Lee, P.A., Selevan, S.G., Juul, A., SØrensen, T.I. and Swan, S.H. (2008) Examination of US Puberty-Timing Data from 1940 to 1994 for Secular Trends: Panel Findings. Pediatrics, 121, S172-S191. https://doi.org/10.1542/peds.2007-1813D

[6] Al-Awadhi, N., Al-Kandari, N., Al-Hasan, T., AlMurjan, D., Ali, S. and Al-Taiar, A. (2013) Age at Menarche and Its Relationship to Body Mass Index among Adolescent Girls in Kuwait. BMC Public Health, 13, 29. https://doi.org/10.1186/1471-2458-13-29

[7] Atay, Z., Turan, S., Guran, T., Furman, A. and Bereket, A. (2011) Puberty and Influencing Factors in Schoolgirls Living in Istanbul: End of the Secular Trend? Pediatrics, 128, e40-e45. https://doi.org/10.1542/peds.2010-2267

[8] Razzaghy-Azar, M., Moghimi, A., Sadigh, N., Montazer, M., Golnari, P., Zahedi-Shoolami, L., et al. (2006) Age of Puberty in Iranian Girls Living in Tehran. An nals of Human Biology, 33, 628-633. https://doi.org/10.1080/03014460600909372

[9] Rokade, S. and Mane, A.A. (2008) Study of Age at Menarche, the Secular Trend and Factors Associated with It. Internet Journal of Biological Anthropology, 3, 1-7.

[10] Codner, E., Unanue, N., Gaete, X., Barrera, A., Mook-Kanamori, D., Bazaes, R. and Avila, A. (2004) Age of Pubertal Events in Chilean School Age Girls and Its Relationship with Socioeconomic Status and Body Mass Index. Revista Medica de Chile, 132, 801-808. https://www.ncbi.nlm.nih.gov/pubmed/15379326

[11] Lalys, L. and Pineau, J.C. (2014) Age at Menarche in a Group of French Schoolgirls. Pediatrics International, 56, 601-604. https://doi.org/10.1111/ped.12296

[12] Oblacińska, A., Jodkowska, M., Tabak, I., Mikiel-Kostyra, K. and Palczewska, I. (2010) Physical Development and Puberty of Polish 13 Year Old Adolescents in the First Decade of 21st Century. Current Status and Secular Trend of Growth and Maturationin the Last 30 Years. Med WiekuRozwoj, 14, 235-245.

[13] Cabanes, A., Ascunce, N., Vidal, E., Ederra, M., Barcos, A., Erdozain, N., et al. (2009) Decline in Age at Menarche among Spanish Women Born from 1925 to 1962. BMC Public Health, 9, 449. https://doi.org/10.1186/1471-2458-9-449

[14] Ayele, E. and Berhan, Y. (2013) Age at Menarche among In-Schooladolescents in Sawla Town, South Ethiopia. Ethiopian Journal of Health Sciences, 23, 189-200.

[15] Gebremariam, H., Gebremariam, A., Tesfay, G., Adem, O.S. and Assefa, H. (2015) Mean Difference of Age at Menarche and Body Mass Index among Government and Private High-School Students of Mekelle City, Northern Ethiopia. Journal of Nutrition \& Food Sciences, S3, 4. https://doi.org/10.4172/2155-9600.S3-004

[16] Raji, Y., Osonuga, O.A., Shittu, O.I., Akinsomisoye, O.S., Togun, V.A. and Azeez, M.O. (2006) Age at Menarche and Its Predicting Factors in Cities of Ibadan and Ogbomoso of Southwestern Nigeria. Journal of Medical Sciences, 6, 772-778. https://doi.org/10.3923/jms.2006.772.778

[17] Mpora, B.O., Piloya, T., Awor, S., Ngwiri, T., Laigong, P., Mworozi, E.A., et al. (2014) Age at Menarche in Relation to Nutritional Status and Critical Life Events among Rural and Urban Secondary School Girls in Post-Conflict Northern Uganda. BMC Women's Health, 14, 66. https://doi.org/10.1186/1472-6874-14-66

[18] Ku, S.Y., Kang, J.W., Kim, H., Kim, Y.D., Jee, B.C., Suh, C.S., et al. (2006) Age at Menarche and Its Influencing Factors in North Korean Female Refugees. Human Reproduction, 21, 833-836. https://doi.org/10.1093/humrep/dei271

[19] Bayat, P.D., Ghanbari, A., Khazaei, M., Ghorbani, R. and Amiri, S. (2012) Age at 
Menarche and Related Factors in Girls of Urban Areas of Markazi (Central) Province of Iran. International Journal of Morphology, 30, 15-18.

https://doi.org/10.4067/S0717-95022012000100002

[20] Adair, L.S. and Gordon-Larsen, P. (2001) Maturational Timing and Overweight Prevalence in US Adolescent Girls. American Journal of Public Health, 91, 642-644. https://doi.org/10.2105/AJPH.91.4.642 